\title{
Photoluminescence Activity of Neodymium-doped Gallium Oxide Thin films
}

\author{
C. Lecerf, P. Marie, C. Frilay, J. Cardin and X. Portier \\ CIMAP-CEA-CNRS UMR 6252-ENSICAEN-Université de Caen, 6 Boulevard Maréchal Juin, \\ 14050 Caen Cedex 4, France
}

\begin{abstract}
Photoluminescence activity was observed for neodymium-doped gallium oxide thin films prepared by radiofrequency magnetron co-sputtering. Structural and optical properties of asgrown and annealed films were studied and photoluminescence activity was especially investigated. The most intense lines were associated to the ${ }^{4} \mathrm{~F}_{3 / 2} \rightarrow{ }^{4} \mathrm{I}_{9 / 2}$ and ${ }^{4} \mathrm{~F}_{3 / 2} \rightarrow{ }^{4} \mathrm{I}_{11 / 2}$ electronic transitions of $\mathrm{Nd}^{3+}$. The effects of deposition and treatment parameters such as the substrate temperature, the post anneal treatment or the neodymium content in the films were particularly examined with the aim to reach the best luminescence efficiency.
\end{abstract}

\section{INTRODUCTION}

Studies of Transparent Conducting Oxide (TCO) semiconductors attract much attention because of their numerous applications in electronic devices, such as flat panel displays, solar cells, waveguides or high-temperature stable gas sensors [1,2,3,4]. Most of these devices require optoelectronic tools which need transparent electrodes, i.e. a thin film of a TCO semiconductor. So far, Indium Tin Oxide (ITO) thin films were mainly used. However, recent developments in optoelectronic devices need transparent thin films electrodes with specific properties, such as lower resistivity and higher optical transmittance [5]. Furthermore, due to the high cost and the limited supply of indium and with the market expansion of optoelectronic devices which need ITO, it appears also an urgent need of alternatives TCOs.

The monoclinic phase of gallium oxide $\left(\beta-\mathrm{Ga}_{2} \mathrm{O}_{3}\right)$ belongs to these promising TCOs. Its wide band gap of about 4.8-5 eV provides the possibility of light emission in the infrared, visible and ultraviolet spectral regions [6,7]. In addition, it presents very high chemically and thermally stabilities (melting point at $1800^{\circ} \mathrm{C}$ ) and can be easily obtained by basic annealing treatments [3]. Optical and luminescent properties of rare-earth doped $\beta-\mathrm{Ga}_{2} \mathrm{O}_{3}$ make this semiconductor particularly interesting [4]. Monoclinic $\beta-\mathrm{Ga}_{2} \mathrm{O}_{3}$ phase can be described by its space group $\mathrm{C}_{2 / \mathrm{m}}$ and cell parameters $a=1.221 \mathrm{~nm} ; b=0.304 \mathrm{~nm} ; c=0.580 \mathrm{~nm}$ and $\beta=103.8^{\circ}$ [8]. $\beta-\mathrm{Ga}_{2} \mathrm{O}_{3}$ thin films have been fabricated with different techniques such as electron beam evaporation [9], spray pyrolysis deposition [10], sol gel process [11], and radiofrequency (RF) magnetron sputtering $[8,12]$.

While in a previous work [8] undoped $\beta-\mathrm{Ga}_{2} \mathrm{O}_{3}$ polycrystalline thin films were mostly studied, the present article is concentrated on neodymium-doped gallium oxide $\left(\mathrm{Ga}_{2} \mathrm{O}_{3}: \mathrm{Nd}^{3+}\right)$. Similarly, $\mathrm{Ga}_{2} \mathrm{O}_{3}: \mathrm{Nd}^{3+}$ thin films have been prepared by RF magnetron co-sputtering. Studies are especially focused on their luminescence properties. Substrate temperature, annealing temperature as well as neodymium content in the film are considered to reveal their influence on the structure and the luminescence. 


\section{EXPERIMENT}

$\mathrm{Ga}_{2} \mathrm{O}_{3}: \mathrm{Nd}^{3+}$ thin films have been fabricated by RF magnetron co-sputtering of a $\mathrm{Ga}_{2} \mathrm{O}_{3}$ target topped by $\mathrm{Nd}_{2} \mathrm{O}_{3}$ pellets. These latter's were placed on the target, and depending on their numbers, they correspond to a surface ratio $\mathrm{S}$ of $4.5 \%, 7 \%, 10 \%$ and $12 \%$. Before deposition, the main chamber was evacuated down to $1.0 \times 10^{-6} \mathrm{mbar}$ and brought to the substrate temperature $\left(\mathrm{T}_{\mathrm{s}}\right.$ ) wanted. $\mathrm{T}_{\mathrm{s}}$ was ranged from $100^{\circ} \mathrm{C}$ up to $600^{\circ} \mathrm{C}$. After this first step, a pure argon pressure was injected, creating a plasma maintained at a pressure of 17 mbar. A power density of 1.85 $\mathrm{W} . \mathrm{cm}^{-2}$ was applied. Layers were grown on (100)-oriented silicon substrates placed at $7 \mathrm{~cm}$ just above the target. Post-annealing treatments were carried out at various annealing temperature $\left(T_{a}\right)$ values during 1 hour under a continuous flow of pure nitrogen. Samples were cooled down to room temperature with a rate of $50^{\circ} \mathrm{C} \cdot \mathrm{s}^{-1}$.

Different techniques were used in order to characterize the films and to analyse their behaviour with the deposition parameters. X-ray spectroscopy measurements were performed using a Philips XPERT diffractometer with $\mathrm{CuK}_{\alpha}(\lambda=1.5418 \AA)$ as X-ray source. Usual $\theta-2 \theta$ diagrams were recorded under a grazing incidence of $0.5^{\circ}$. Ellipsometric Spectroscopy (ES) measurements were made thanks to a Jobin-Yvon ellipsometer (UVISEL). The incidence angle of the light on the film surface was $66.2^{\circ}$ and data were collected between 1.5 and $4.5 \mathrm{eV}$. A dispersion law which models the dielectric function of $\mathrm{Ga}_{2} \mathrm{O}_{3}$ was used [8].

A JEOL 2010F Transmission Electron Microscope (TEM) allowed cross-sectional views of the films. To be performed, electron beam was generated with a Field Electron Gun source at $200 \mathrm{kV}$ and a CCD camera was used to acquire images.

Photoluminescence (PL) measurements were made using a Coherent INNOVA 90C CW Argon laser operated at $514 \mathrm{~nm}$ as an excitation source. The laser beam was chopped at $20 \mathrm{~Hz}$ by a Thorlabs chopper and focused through a system of lens and mirrors on samples. The $\mathrm{Nd}^{3+} \mathrm{PL}$ was measured at room temperature thanks to a Jobin-Yvon monochromator and with a Northcoast Germanium detector cooled with liquid nitrogen. The PL signal was recorded on a personal computer via a SRS lock-in amplifier referenced to the chopper frequency.

\section{RESULTS AND DISCUSSION}

\section{$\underline{\text { As-grown } \mathrm{Ga}_{2}} \underline{\mathrm{O}}_{3}: \mathrm{Nd}^{3+}$ thin films}

The ellipsometric spectroscopy allows obtaining the thickness, the real part of the refractive index and the absorption coefficient ( $\alpha$ ) of the deposited materials. Figure 1(a) is a plot of the thickness dependence of doped as-grown films versus deposition time for different substrate temperatures $\left(100^{\circ} \mathrm{C}, 300^{\circ} \mathrm{C}\right.$ and $\left.600^{\circ} \mathrm{C}\right)$. It clearly shows that films are as thicker as the deposition time is increased. Similar trend is observed when $\mathrm{T}_{\mathrm{S}}$ is lowered. These results are in good agreement with those found for undoped films [8]. Deposition rates were calculated: 681 $\mathrm{nm} \cdot \mathrm{h}^{-1}, 652 \mathrm{~nm} \cdot \mathrm{h}^{-1}$ and $455 \mathrm{~nm} \cdot \mathrm{h}^{-1}$ for films grown at $\mathrm{T}_{\mathrm{S}}=100^{\circ} \mathrm{C}, 300^{\circ} \mathrm{C}$ and $600^{\circ} \mathrm{C}$, respectively. Thicknesses were also measured thanks to TEM observations and the values were consistent. A low $T_{s}$ value is then better in terms of deposition rate. This result means that the sticking ability of $\mathrm{Ga}$ and $\mathrm{O}$ is attenuated when $\mathrm{T}_{\mathrm{s}}$ is high. This is most probably due to the high degree of volatility of these two species at high temperature.

Regarding the static refractive indices, they have been found very close to that of the bulk material (1.96 at $1060 \mathrm{~nm}$ [14]) as noticed for undoped $\mathrm{Ga}_{2} \mathrm{O}_{3}$ thin films [8]. 
Absorption coefficients $(\alpha)$ values were calculated and their dependence versus $T_{\mathrm{s}}$ is represented in Figure 1(b). The behaviour of doped films prepared at $\mathrm{T}_{\mathrm{s}}=100^{\circ} \mathrm{C}, 300^{\circ} \mathrm{C}$ and $600^{\circ} \mathrm{C}$ and that of an undoped film prepared at $100^{\circ} \mathrm{C}$ are reported. For a first range of energy values from 1.5 to $3.5 \mathrm{eV}$, the $\alpha$ values of all these films are similar and constant with low values. This transparency extends to almost $4.0 \mathrm{eV}$ for the doped films. For a second range to 5.0 $\mathrm{eV}, \alpha$ values increase exponentially whatever the $\mathrm{T}_{\mathrm{s}}$ value and the doping. Among all the studied samples, the doped film prepared at $\mathrm{T}_{\mathrm{s}}=600^{\circ} \mathrm{C}$ keeps a better transparency.
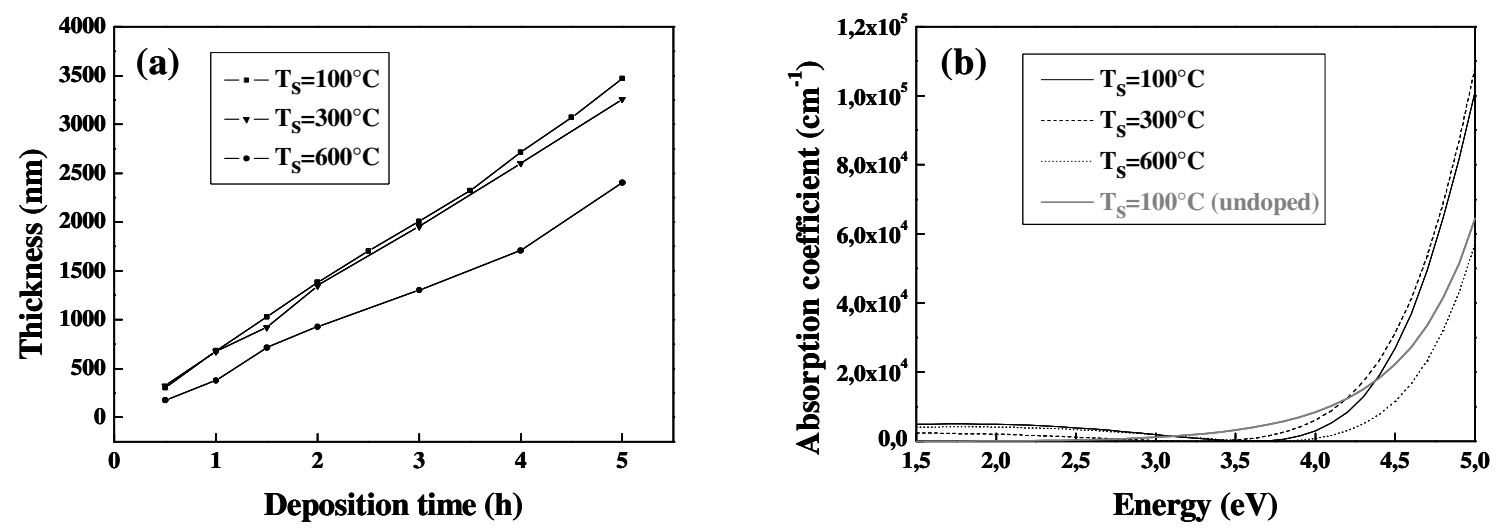

Figure 1. (a) Dependence of the thickness on the deposition time and the substrate temperature for doped as-grown films $(\mathrm{S}=14 \%)$;

(b) Dependence of the absorption coefficient versus substrate temperature for as-grown films $(\mathrm{S}=14 \%)$.

Regarding the structural properties, as it has already been observed for undoped films, all the as-grown films are found to be amorphous whatever the chosen $\mathrm{T}_{\mathrm{s}}$ value. Furthermore, they do not exhibit any PL activity.

\section{$\underline{\text { Annealed } \mathrm{Ga}_{2}} \underline{\mathrm{O}}_{3} \underline{\mathrm{Nd}^{3+} \text { thin films: structural properties }}$}

Post-annealing treatments allow the stable $\beta-\mathrm{Ga}_{2} \mathrm{O}_{3}$ phase to be formed. XRD spectra and TEM observations of undoped thin films have confirmed it and established the optimal $\mathrm{T}_{\mathrm{a}}$ value at $1000^{\circ} \mathrm{C}[8]$.

Figure 2(a) shows the XRD spectra of $\mathrm{Ga}_{2} \mathrm{O}_{3}: \mathrm{Nd}^{3+}$ thin films annealed during 1 hour at $1000^{\circ} \mathrm{C}$, one have been prepared at $\mathrm{T}_{\mathrm{a}}=100^{\circ} \mathrm{C}$ and the other at $600^{\circ} \mathrm{C}$. XRD spectrum of an undoped film deposited at $100^{\circ} \mathrm{C}$ has been reminded [8]. Diffraction peaks appear for both doped samples and their positions are once again consistent with the $\beta-\mathrm{Ga}_{2} \mathrm{O}_{3}$ monoclinic structure. Higher intensities are observed for the doped samples indicating an higher degree of crystallinity of the $\beta-\mathrm{Ga}_{2} \mathrm{O}_{3}$ phase. The variation of peak intensities may be due to a different texture between the films. The undoped $100^{\circ} \mathrm{C}$-deposited films has a (400) preferred orientation [8], and the same (400) texture can be clearly observed for the doped film prepared at $600^{\circ} \mathrm{C}$. This is less obvious for the doped film prepared at $100^{\circ} \mathrm{C}$.

Figure 2(b) is a typical dark field TEM image of a film annealed at $1000^{\circ} \mathrm{C}$. The grain orientation reveals a columnar growth of the film. Columns are approximately $50 \mathrm{~nm}$ wide. Figure 2(c) is the associated selected area diffraction pattern. This latter is in accordance with the monoclinic structure of $\mathrm{Ga}_{2} \mathrm{O}_{3}$ and the grain orientation is also consistent with the above mentioned (400) texture of the films. 

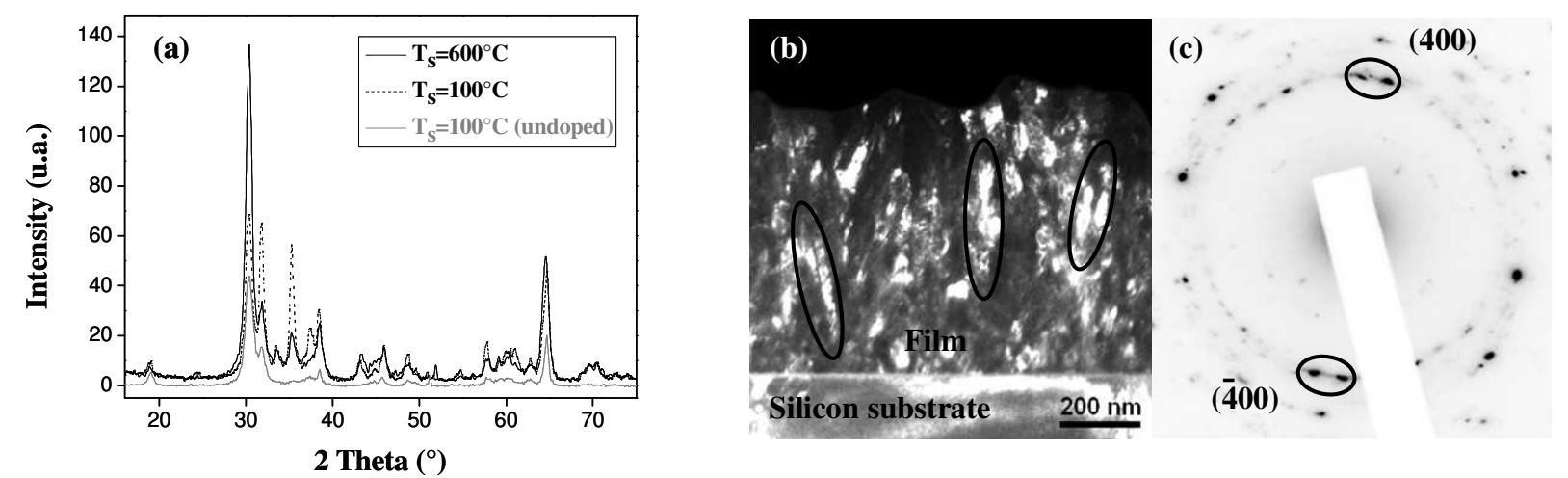

Figure 2. (a) X-ray patterns of annealed films at $1000^{\circ} \mathrm{C}(\mathrm{S}=14 \%)$;

(b) Dark field TEM image of an annealed doped film ( $\mathrm{S}=14 \%)$; (c) Corresponding diffraction pattern.

\section{$\underline{\text { Annealed } \mathrm{Ga}_{2}} \underline{\mathrm{O}}_{3}: \mathrm{Nd}^{3+}$ thin films: optical properties}

Figure 3 describes the evolution of the $\alpha$ values (from $1.5 \mathrm{eV}$ up to $5 \mathrm{eV}$ ) for films grown at $\mathrm{T}_{\mathrm{s}}=600^{\circ} \mathrm{C}$ before and after annealing at $\mathrm{T}_{\mathrm{a}}=1000^{\circ} \mathrm{C}$. Behaviour of an annealed undoped film is also indicated for comparison [8]. As observed for undoped films, the anneal treatment favours the transparent character of the films. $\mathrm{Nd}^{3+}$ doped films are almost transparent for low energies, extending to $4.0 \mathrm{eV}$ and $4.3 \mathrm{eV}$ for the as-grown and annealed films, respectively. However, $\mathrm{Nd}^{3+}$ doping has slightly lowered the transparency of the annealed films for energies lower than $4.0 \mathrm{eV}$. For higher energies (up to $5 \mathrm{eV}$ ), $\alpha$ increases exponentially but the doped films are more transparent than the undoped ones. It is conceivable that due to the growth process, the films have a lower oxygen content than the target. The use of $\mathrm{Nd}_{2} \mathrm{O}_{3}$ pellets could partly compensate this oxygen deficiency in the $\mathrm{Ga}_{2} \mathrm{O}_{3}$ matrix. Consequently, one can expect a better film stoechiometry leading to a better transparency.

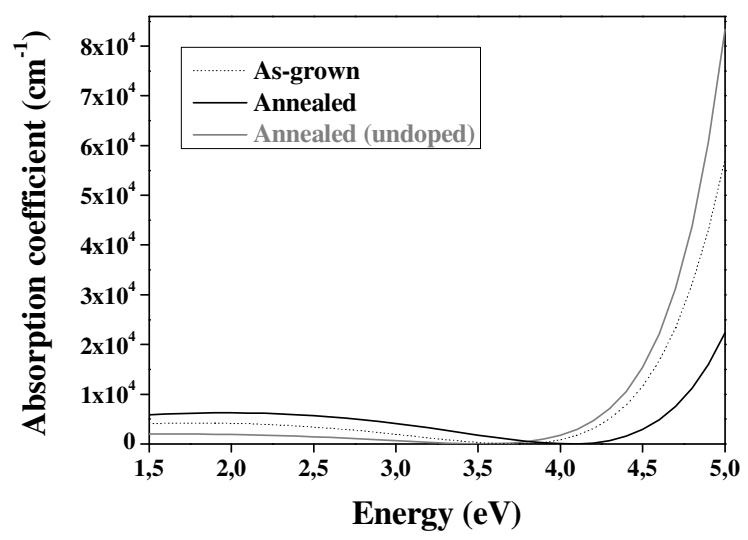

Figure 3. Absorption coefficients in the visible spectral region for annealed films at $\mathrm{T}_{\mathrm{a}}=1000^{\circ} \mathrm{C}$ and $\mathrm{S}=14 \%$ for the doped films.

\section{$\underline{\text { Annealed Ga }} \underline{\mathrm{O}}_{3} \underline{\mathrm{Nd}^{3+} \text { thin films: photoluminescent properties }}$}

PL activity of $\mathrm{Ga}_{2} \mathrm{O}_{3}: \mathrm{Nd}^{3+}$ thin films showed clearly the $\mathrm{Nd}^{3+}$ broad transitions centred at $900 \mathrm{~nm}$ and $1070 \mathrm{~nm}$ corresponding to $4 \mathrm{~F}$ transitions ${ }^{4} \mathrm{~F}_{3 / 2} \rightarrow{ }^{4} \mathrm{I}_{9 / 2}$ and ${ }^{4} \mathrm{~F}_{3 / 2} \rightarrow{ }^{4} \mathrm{I}_{11 / 2}$, respectively 
[8]. All those bands are crystal-field split and therefore broadened. To complement these first results, the effects of the annealing temperature and the $\mathrm{Nd}^{3+}$ content in films were studied. All spectra were normalized with the film thicknesses.

The $100^{\circ} \mathrm{C}$-deposited films are chosen to study the effect of the annealing temperature on PL activity. Figure 4 exhibits the dependence of the $T_{a}$ value on the PL response for samples prepared at $\mathrm{T}_{\mathrm{s}}=100^{\circ} \mathrm{C}$ during 6 hours with $\mathrm{S}=7 \%$. Three films annealed at 900,1000 and $1100^{\circ} \mathrm{C}$ are represented. The 900 and $1070 \mathrm{~nm}$ transitions are clearly observed. These results show that an anneal treatment at $1000^{\circ} \mathrm{C}$ leads to the highest intensity of luminescence.

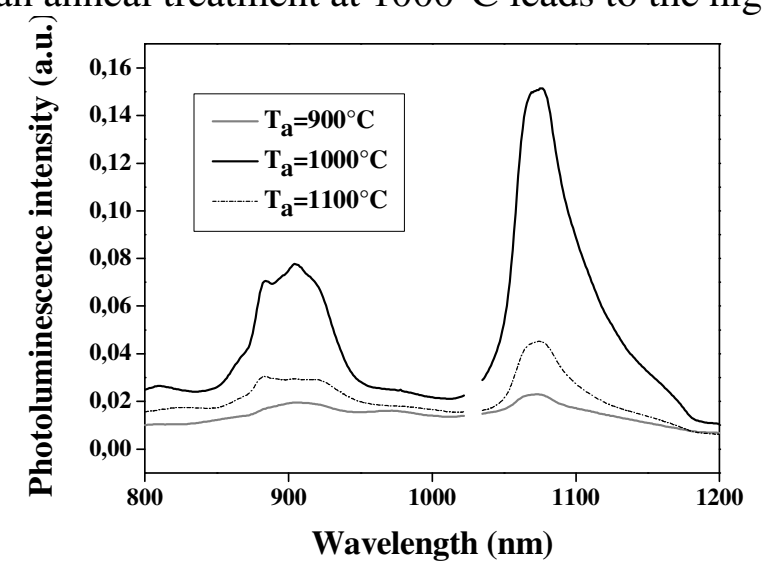

Figure 4. Dependence of the annealing temperature value on photoluminescence response for a 7 $\%$ surface ratio and $a 100^{\circ} \mathrm{C}$ substrate temperature. The second order laser ray at $1028 \pm 15 \mathrm{~nm}$ has been removed for more visibility.

Figure 5 presents PL activity of films prepared at $100^{\circ} \mathrm{C}$ and annealed at $1000^{\circ} \mathrm{C}$ but with different $\mathrm{S}$ values $(4.5 \%, 7 \%, 10 \%$ and $12 \%)$. The $4.5 \%$ and $12 \% \mathrm{~S}$ values exhibit the lower activity. Nevertheless, the two main transitions at about 900 and $1070 \mathrm{~nm}$ are observed. Intermediary $\mathrm{Nd}^{3+}$ contents lead to the best PL activities. For $\mathrm{S}=10 \%$ the activity of the film at $900 \mathrm{~nm}$ is twice as much efficient than for a $7 \%$ one. At $1070 \mathrm{~nm}$, comparison is difficult because of the silicon emission [13]. This emission is explained by the consequences of the doping of the substrate.

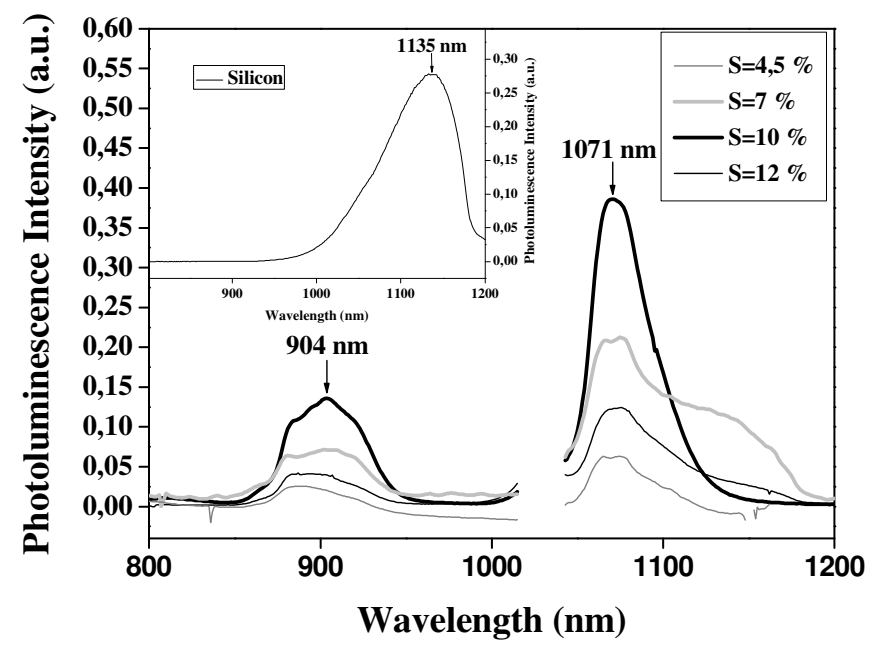

Figure 5. Dependence of the $\mathrm{Nd}^{3+}$ surface ratio on the photoluminescence activity for films prepared at $100^{\circ} \mathrm{C}$ and annealed at $1000^{\circ} \mathrm{C}$; the inset shows the PL activity of a silicon substrate. 


\section{CONCLUSIONS}

$\mathrm{Ga}_{2} \mathrm{O}_{3}: \mathrm{Nd}^{3+}$ thin films have been successfully grown by RF magnetron sputtering. Analyses on these thin films have confirmed the precedent paper observations about structural and optical properties. Indeed, the $\beta-\mathrm{Ga}_{2} \mathrm{O}_{3}$ phase of annealed films is observed, the best (400) texture being obtained for $\mathrm{T}_{\mathrm{a}}=1000^{\circ} \mathrm{C}$. Furthermore, the $1000^{\circ} \mathrm{C}$-annealed films are transparent in the 1.5-4.3 eV range. Concerning photoluminescence in the infrared region, ${ }^{4} \mathrm{~F}_{3 / 2} \rightarrow{ }^{4} \mathrm{I}_{9 / 2}$ and ${ }^{4} \mathrm{~F}_{3 / 2} \rightarrow{ }^{4} \mathrm{I}_{11 / 2}$ electronic transitions of $\mathrm{Nd}^{3+}$ are observed. Samples presenting the most intense luminescence correspond to the following parameters values: $\mathrm{T}_{\mathrm{s}}=100^{\circ} \mathrm{C}, \mathrm{S}=10 \%$ and $\mathrm{T}_{\mathrm{a}}=1000^{\circ} \mathrm{C}$. However, at about $1135 \mathrm{~nm}$, the silicon substrate emission can partially hide the ${ }^{4} \mathrm{~F}_{3 / 2} \rightarrow{ }^{4} \mathrm{I}_{11 / 2}$ transition (at 1070nm).

To avoid this silicon substrate contribution, thin films on quartz will be tested. In a near future, thin films will be fabricated with calibrated $\mathrm{Nd}_{2} \mathrm{O}_{3}$ pellets. It will be thus easier to control the $\mathrm{Nd}^{3+}$ content in the films. Chemical analyses will be also performed to quantify the $\mathrm{Nd}^{3+}$ concentration as the well as the stoechiometry of the films. The influence of the $\mathrm{Nd}^{3+}$ content in the doped films on its transparent behaviour will be then studied.

The aim being to fabricate electroluminescent device such as a Light Emitting Diode, electroluminescence properties will be soon investigated.

\section{REFERENCES}

1. R. G. Gordon, MRS Bull., 52, (2000).

2. Z. Liu and al., Sens. Actuators B2 129, 666 (2008).

3. M. Bartic, Y. Toyoda, C.-I. Baban and M. Ogita, J. Appl. Phys. 45, 5186 (2006).

4. E. Nogales, J.A. Garcia, B. Méndez and J. Piqueras, Appl. Phys. Lett. 91, 133108 (2007).

5. T. Minami, Semicond. Sci. Technol. 20, 35 (2005).

6. E. Nogales, B. Méndez and J. Piqueras, Appl. Phys. Lett. 86, 113112 (2005).

7. H. Ohta, K. Nomura, H. Hiramatsu, K. Ueda, T. Kamiya, M. Hirano, H. Hosono, Sol. State Electronics 47, 2261-2267 (2003).

8. P. Marie, X. Portier, J. Cardin, Phys. Stat. Sol. 205, 1943 (2008).

9. A. Callegari, P.D. Hoh, D.A. Duchanan, and D. Lacey, Appl. Phys. Lett. 54, 332 (1989).

10. J. Hao and M. Cocivera, J. Phys. D: Appl. Phys. 35, 433 (2002).

11. T. Miyata, T. Nakatani and T. Minama, J. of Luminescence 87-89, 1183 (2000).

12. T. Minami, H. Yamada, Y. Kubota, T. Myata and Y. Sakagami, Proc. Of the Fourth International Display Workshops, 605 (1997).

13. L.T Canham, Appl. Phys. Lett. 57, 1046 -1048 (1990).

14. R. Adair, L. Chase and Stephen A. Payne, Phys. Review B 39, 3337-3349 (1989). 